\title{
Malignancy in Clinically Non-toxic Multinodular Goiter
}

\author{
Mohd. Shahjahan Ali, ${ }^{1}$ Md. Habibullah Sarkar, ${ }^{2}$ Syeda Momena Hossain ${ }^{3}$
}

\begin{abstract}
Objective: Goiter is a common form of thyroid swelling among population living in areas of iodine deficiency. Of the goiters, non-toxic multinodular goiter (MNG) is the most common and benign form of thyroid disease. However, studies have shown that long-standing MNGs may harbour malignancy. The present study was, therefore, undertaken to ascertain the prevalence of malignancy in clinically diagnosed non-toxic MNGs.

Methods: This cross-sectional study was conducted in the Department of Surgery (all four-units) and ENT Department, Rajshahi Medical College Hospital, Rajshahi from July 2007 to June 2008 on 100 patients of clinically non-toxic MNG who underwent thyroid surgery. Biopsy materials were taken from the excised nodules and were sent for histopathological examination to see what proportion of them harboured malignancy.

Result: The findings of the study showed that $40 \%$ of patients were $30-40$ years old with mean age of the patients being $35.5 \pm 10.1$ (range: $14-75$ ) years. Majority (87\%) of the patients was female. Half of the patients with non-toxic MNGs had a history of thyroid swelling for 1-5 years and the rest half for $>5$ years with median duration of illness being 5.5 years (range: $1-30$ years). Of the 100 patients $4 \%$ had stridor and $6 \%$ dyspnoea; dysphagia and cervical lymphadenopathy each was $6 \%$. Nearly $60 \%$ of the patients had goiter of size $15 \mathrm{sq-cm}$ or below. Sub-total thyroidectomy was the most common operation performed (33\%) followed by right hemi-thyroidectomy (24\%), near total thyroidectomy $(20 \%)$, left hemi-thyroidectomy $(18 \%)$ and total thyroidectomy (5\%). Histopathological examination of resected specimens revealed that $15 \%$ of the MNGs had malignancy with papillary to follicular carcinoma ratio being $4: 1$. Histopathological typing showed that $79 \%$ was simple MNGs, $4 \%$ follicular adenoma, $12 \%$ papillary carcinoma, $3 \%$ follicular carcinoma and $2 \%$ chronic thyroiditis. Neither age nor sex was found to be associated with presence of malignancies in MNGs ( $p=0.865$ and $p=0.647$ respectively). The goiter-size was also not associated with presence of malignancies $(p=0.691)$. However, the mean duration of thyroid swelling in patients who had malignancy was much higher ( 8.5 years) than that in patients who did not haveany malignancy $(5.7$ years $)(p=0.024)$.
\end{abstract}

Conclusion: The study concluded that a small proportion of long-standing non-toxic MNGs may turn into malignancy. Therefore, routine operative treatment without confirming that the cases are malignant does not seem to be justified.

Key words: Malignancy and non-toxic multinodulargoiter etc.

\section{INTRODUCTION:}

Goiter, arising from thyroid gland, is a common form of neck swelling among population living in areas of iodine deficiency. This condition has largely disappeared in many parts of the world as a consequence of routine use of iodized salt and iodination of fertilizers, animal feeds and preservatives. ${ }^{1}$ A large cross-sectional study in Spain reported nontoxic multinodular goiter $(51.3 \%)$ as the most common form of goiter, followed by toxic multinodular goiter $(23.8 \%)$. Other causes of goiter were solitary thyroid

\section{Authors' information:}

'Dr. Mohd. Shahjahan Ali, Assistant Professor, Department of Surgery, Rajshahi Medical College, Rajshahi

${ }^{2}$ Prof. Dr. Md. Habibullah Sarkar, Department of Surgery, Rajshahi Medical College, Rajshahi

${ }^{3}$ Dr. Syeda Momena Hossain, Student of MS (Surgery) Phase- B, Resident, Rajshahi Medical College, Rajshahi

Correspondence: Dr. Mohd. Shahjahan Ali, Phone: +880 1711373934, E-mail:withshahjahan@gmail.com 
nodules $(9.8 \%)$, toxic adenoma (5\%), Graves' disease $(4.3 \%)$, Hashimoto's thyroiditis (3.9\%), simple goiter $(1.3 \%)$ and thyroiditis $(0.5 \%){ }^{2}$ Non-toxic or simple goiter may develop as a result of stimulation of the thyroid gland by thyroid stimulating hormone (TSH), either as a result of inappropriate secretion from a micro adenoma in the anterior pituitary or in response to a chronically low level of circulating thyroid hormone. ${ }^{3}$

Thyroid nodules can represent benign adednomas, cancer, cysts, or inflammation. Nodules with poor radio-iodine uptakemay present as benign lesions, suspicious for malignancy. Follicular thyroid cancer (FTC) is the second most common tumor of the thyroid gland and constitutes approximately $15 \%$ of all thyroid cancers. ${ }^{4}$ The likelihood of developing malignancy increases with duration of multinodular goiter as reported by Mathai et $\mathrm{al}^{5}$. They reported a mean duration swelling for 9.1 years in case of multinodular goiter as opposed to an average of 5.5 years for those with only nodular goiter. The prevalence of carcinoma in MNG has been reported to be $5-10 \%$. Therefore, FNAC should be done invariably to reach a diagnosis and resection for suspicious lesions. ${ }^{6}$

Follicular thyroid cancer tends to be more common in areas of iodine deficiency. As Bangladesh is an endemic zone for iodine deficiency goiter, MNG is commonly encountered by the physicians. Different studies have shown that the incidence of malignant changes in MNG is no less. So, high index of suspicion bears utmost significance in case of MNGs. The outcome of MNG coexisting with thyroid malignancy is excellent-if the malignant change is detected earlier and is managed accordingly. In contrast, the outcome of thyroid carcinoma with advanced stage is disappointing. So, detection of thyroid cancer in early stage by histopathological examination of all resected thyroid tissue is the key toreduce mortality. The present study was, therefore, an attempt to find the prevalence of malignancy in patients with non-toxic MNGs who were operated in Rajshahi Medical College Hospital for thyroid enlargements as well as to see whether the duration of swelling had any impact on malignant changes in MNGs.

\section{METHODS:}

This hospital-based cross-sectional study was carried out in the Departments of General Surgery and ENT, Rajshahi Medical College Hospital, Rajshahi between July, 2007 to June, 2008. Clinically diagnosed patients of non-toxic MNG admitted in the above-mentioned departments to receive surgical treatment were the study population. The patients of any age of either sex were included. Clinically suspected cases of thyroid malignancy, preoperatively diagnosed thyroid malignancy and clinically diagnosed solitary thyroid nodules were excluded. A total of 100 patients were included in the study. Having obtained ethical clearance from the Ethical Committee and verbal consent from the patients, the data collection was commenced. Data processing and analysis were done using SPSS (statistical package for social sciences), version 16. The test statistics used to analyze the data were descriptive statistics like frequency with corresponding percentage, mean and standard deviation (SD), while the analytical tests used were Chi-square $\left(\chi^{2}\right)$ and Student's t-Test. The level of significance was set at $5 \%$ and $p$-value < 0.05 was considered significant.

\section{RESULTS:}

Age distribution of the patients shows that over $40 \%$ of the patients were between $30-40$ years old followed by $31 \%$ between $40-50$ years, $13 \%$ between $20-30$ years, $7 \% 50$ years or above and the rest $6 \%$ below 20 years of age. The mean age was $35.5 \pm 10.1$ years (range: $14-75$ years). Majority $(87 \%)$ of the patients was female with male to female ratio being roughly $1: 7$. Half $(50.0 \%)$ of the patients at presentation had been suffering from the non-toxic MNG for 1-5 years and the rest half for more than 5 years. The median duration of illness was 5.5 years (range: 1-30 years)(table I). All of the patients exhibited neck swelling. Out of 100 patients, 4\% had stridor, $6 \%$ dyspnoea and another $6 \%$ had dysphagia (Fig 1). Most (60\%) of the patients had butterfly shaped goiter and $28 \%$ had unilateral conical goiter. However, a small number of 
patients (12\%) exhibited irregular shaped goiter. Nearly $60 \%$ of the patients had goiter of size 15 or $<15 \mathrm{sq}-\mathrm{cm}$ and $42 \%$ had $>15 \mathrm{sq}-\mathrm{cm}$. Majority (94\%) of the patients exhibited no cervical lymphadenopathy (table IV). Only 6\% had cervical lymphadenopathy. Study of associated co-morbidities shows that 1 had hypertension, 4 had diabetes and 2 had bronchial asthma (Fig 2).

Sub-total thyroidectomy was performed on one-third (33\%) of the patients followed by right hemithyroidectomy (24\%), near total thyroidectomy $(20 \%)$, left hemi thyroidectomy (18\%) and total thyroidectomy (5\%) (Fig 3). Histopathological diagnosis revealed that nearly $80 \%$ of the patients had MNG, $4 \%$ follicular adenoma, $12 \%$ papillary carcinoma, $3 \%$ follicular carcinoma and $2 \%$ chronic thyroiditis. Thus, out of 100 cases 15 (12 papillary carcinoma and 3 follicular carcinoma) were malignant and the rest 85 were benign (Table III).

\begin{tabular}{|c|c|c|}
\hline Demographic characteristics & Frequency & Percentage \\
\hline \multicolumn{3}{|l|}{ Age* $^{*}$ (years) } \\
\hline$<20$ & 06 & 6.0 \\
\hline $20-30$ & 13 & 13.0 \\
\hline $30-40$ & 43 & 43.0 \\
\hline $40-50$ & 31 & 31.0 \\
\hline$\geq 50$ & 07 & 7.0 \\
\hline \multicolumn{3}{|l|}{ Sex } \\
\hline Male & 13 & 13.0 \\
\hline female & 87 & 87.0 \\
\hline \multicolumn{3}{|l|}{ Duration of illness** (years) } \\
\hline$\leq 5$ & 50 & 50.0 \\
\hline$>5$ & 50 & 50.0 \\
\hline
\end{tabular}

*Mean age $=(35.5 \pm 10.1)$ years; range $=(14-75)$ years.

**Median duration of illness $=5.5$ years; range $=(1-30)$ years.

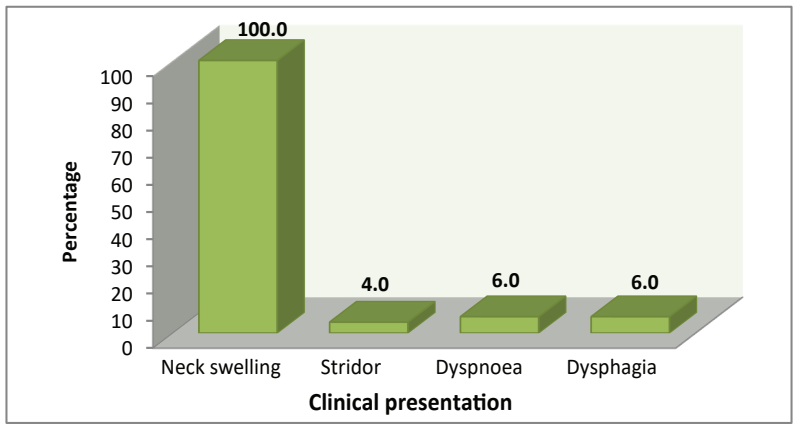

Fig 1: Demonstrates the clinical presentation of the patients $(n=100)$

\begin{tabular}{|c|c|c|}
\hline $\begin{array}{l}\text { Morphological } \\
\text { characteristics of goitre }\end{array}$ & Frequency & Percentage \\
\hline \multicolumn{3}{|l|}{ Goitre shape } \\
\hline Unilateral conical & 28 & 28.0 \\
\hline Butterfly & 60 & 60.0 \\
\hline Irregular & 12 & 12.0 \\
\hline \multicolumn{3}{|l|}{ Goitre size } \\
\hline$\leq 15 \mathrm{sq}-\mathrm{cm}$ & 58 & 58.0 \\
\hline$>15 \mathrm{sq}-\mathrm{cm}$ & 42 & 42.0 \\
\hline \multicolumn{3}{|c|}{ Cervical lymphadenopathy } \\
\hline Yes & 6 & 6.0 \\
\hline No & 94 & 94.0 \\
\hline
\end{tabular}

Table IV shows that $60 \%$ of malignant and $57.6 \%$ benign cases were 35 or below 35 years of age with no significant association being observed between age and prevalence of malignancy in non-toxic multinodular goiter $(p=0.865)$. Both malignant and benign tumours were identically distributed in males and females. Neither sex tends to be associated with harboring malignancy in non-toxic MNGs $(p=0.647)$. Patients who developed malignancy had significantly higher mean duration of illness ( 8.5 years) than those who did not develop malignancy (mean duration was 5.7 years) $(p=0.024)$. Goiter-size was, however, not found to be associated with the development of malignancy $(p=0.691)$.

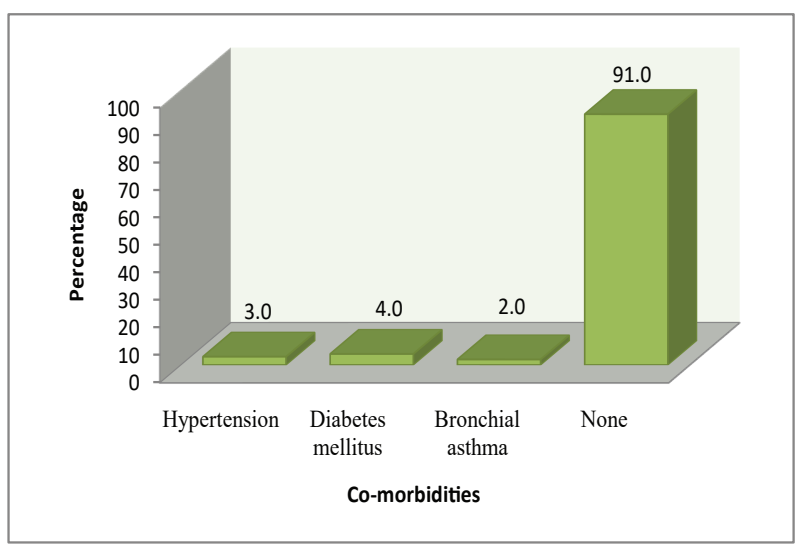

Fig 2: Distribution of patients by Co-morbidities 


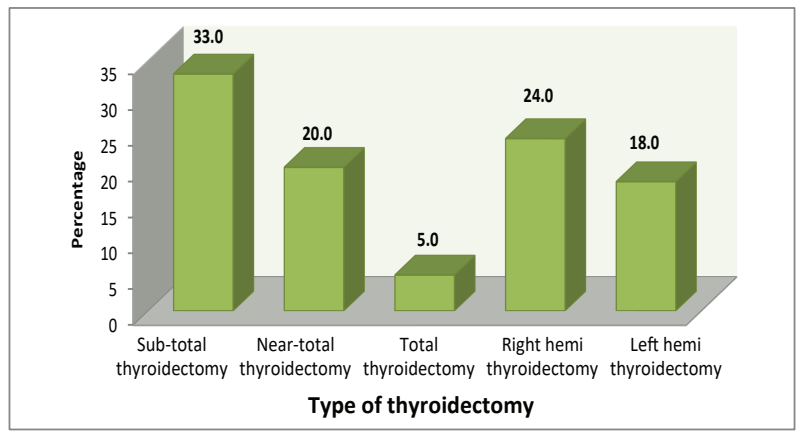

Fig 3: Distribution of patients by Co-morbidities

\begin{tabular}{|lcc|}
\hline Table III. Distribution of patients by diagnosis $(\mathbf{n = 1 0 0 )}$ \\
\hline $\begin{array}{l}\text { Histopathological } \\
\text { diagnosis }\end{array}$ & Frequency & Percentage \\
\hline Multinodular goiter & 79 & 79.0 \\
Follicular adenoma & 4 & 4.0 \\
Papillary carcinoma & 12 & 12.0 \\
Follicular carcinoma & 3 & 3.0 \\
Chronic thyroiditis & 2 & 2.0
\end{tabular}

Table IV. Association of demographic and morphologic features of MNGs with malignancy

\begin{tabular}{|c|c|c|c|}
\hline \multirow[b]{2}{*}{ Variables } & \multicolumn{2}{|c|}{ Diagnosis } & \multirow[b]{2}{*}{ p-value } \\
\hline & $\begin{array}{l}\text { Benign } \\
(n=85)\end{array}$ & $\begin{array}{c}\text { Malignant } \\
(n=15)\end{array}$ & \\
\hline \multicolumn{4}{|l|}{ Age\# (years) } \\
\hline$\leq 35$ & 49(57.6) & $9(60.0)$ & 0.865 \\
\hline$>35$ & $36(42.4)$ & $6(40.0)$ & \\
\hline \multicolumn{4}{|l|}{ Sex\# } \\
\hline Male & 10(11.8) & $3(20.0)$ & 0.647 \\
\hline Female & 75(88.2) & $12(80.0)$ & \\
\hline Duration of MNGs* (years) & $5.7 \pm 4.1$ & $8.5 \pm 4.2$ & 0.024 \\
\hline \multicolumn{4}{|l|}{ Goitre size (sq-cm) } \\
\hline$\leq 15$ & $50(58.8)$ & $8(53.3)$ & 0.691 \\
\hline$>15$ & $35(41.2)$ & 7(46.7) & \\
\hline
\end{tabular}

Figure in the parentheses denoted corresponding percentage. \#Data were analyzed using Chi-square $\left(\chi^{2}\right)$ Test;

*Data were analysed using Unpaired t-Test and were presented as mean $\pm \mathrm{SD}$.

\section{DISCUSSION:}

The term nontoxic or simple goiter indicates an increase in the mass of the thyroid gland resulting from excessive replication of benign thyroid epithelial cells. In patients with nontoxic goiter, thyroid hormone values usually are normal. The increase in thyroid size is a slow process evolving over many years, starting with a diffuse initial enlargement, which frequently becomes multinodular with time. ${ }^{7}$ Multinodular goiter is quite often associated with thyroid carcinoma, but the risk factors for malignancy are not well known. ${ }^{8}$

The findings of the present study showed that a substantial proportion of patients (40\%) was in their $3^{\text {rd }}$ decades of life. The mean age was $35.5 \pm 10.1$ years (range: $14-75$ years). Majority $(87 \%)$ of the patients was female. Half of the patients with non-toxic MNG had a history of suffering from 1-5 years and the rest half for $>5$ years. The median duration of illness was 5.5 years. Of the 100 patients, $4 \%$ had stridor, $6 \%$ dyspnoea and another $6 \%$ had dysphagia. Nearly $60 \%$ of the patients had goiter size $\leq 15 \mathrm{sq}-\mathrm{cm}$. Nearly $95 \%$ of the patients exhibited no cervical lymphadenopathy. Out of 100 patients, 3 had hypertension, 4 diabetes mellitus and 2 bronchial asthma and were operated after proper optimization. Subtotal thyroidectomy was the most frequently performed operation (33\%) followed by right hemithyroidectomy (24\%), near total thyroidectomy $(20 \%)$, left hemi-thyroidectomy $(18 \%)$ and total thyroidectomy (5\%).

Histopathological diagnosis demonstrates that 15\% of the MNGs had malignancy with papillary to follicular carcinoma ratio being 4:1. Rios and associates $^{8}$ found 59 cases of thyroid carcinoma in their series of 672 study subjects giving a prevalence of thyroid carcinoma in MNGs of $8.8 \%$. The most common histological type was papillary carcinoma $(7.1 \%)$, followed by follicular carcinoma $(1 \%)$ and others thus favouring the findings of the present study. Fioretti and colleagues ${ }^{9}$ in a case-control study in Italy demonstrated a history of benign thyroid disease in $18.9 \%$ of 399 histologically confirmed incident thyroid cancers. In another retrospective review of 107 patients operated on for MNG, $7.5 \%$ was found to harbor malignancies with papillary carcinoma being the most common variety. ${ }^{10}$ al-Saleh and al-Kattan ${ }^{11}$ in an attempt to study the prevalence of carcinoma in MNG in Saudi Arabia showed malignant changes in $10 \%$ of the MNGs after histopathological examination. Seventy five percent of the carcinomas 
seen in MNGs were of the papillary type. The investigators also reported that in almost none of the cases, it was possible to discover the malignancy preoperatively suggesting surgical intervention in all nodules/goiters irrespective of being solitary or multinodular. However, this recommendation must be considered with utmost caution in the light of current medical and conservative treatment particularly in the context of Bangladesh. A retrospective study of 361 thyroid specimens during 6 and a 1/2-year period demonstrated $8 \%$ of MNG and $15.2 \%$ of the solitary nodules to be associated with malignancy. The study also observed that malignancy was significantly common in females with solitary nodules (SN) than those with multinodular goiter $(p=0.03)$ and generally occurred at a significantly older age $(p<0.05),{ }^{12}$ although in the present study neither age nor sex was found to be associated with harboring malignancy in non-toxic MNGs ( $p>0.05$ ). However, Mathai and associates $^{5}$ observed a very low prevalence of thyroid carcinoma (4.1\%) in MNGs with an almost equal ratio of papillary to follicular carcinomas. Irshad and associates ${ }^{13}$ observed an even low incidence of thyroid cancer in non-toxic MNG patients $(2.5 \%)$.

As hypothesized long-standing multinodular goiter harbors malignancy, it was observed that the mean duration of thyroid swelling in patients who developed malignancy was significantly higher (8.5 years) than those who did not develop so (5.7 years $)(p=0.024)$. Consistent with this finding Mathai et $\mathrm{al}^{5}$ also found patients with longer duration of MNGs (mean duration 9.1 years) to harbour malignancy more frequently, than those with shorter duration of MNGs (mean duration of swelling 5.5 years $)(p<0.01)$.

\section{CONCLUSION:}

The present study demonstrated a low prevalence of carcinoma in non-toxic MNGs. The study also found a significantly higher presence of malignancy in patients with long standing MNGs than that in patients with shorter duration of thyroid swelling. The study did not find any association of harboring malignancy in MNGs with either age or sex. Nor did it find any association of malignancy with size of the swelling. As only 1 in 7 of the MNGs in the present study exhibited malignant change, mandatory operation for the condition is not advocated. Since clinical characteristics cannot predict malignancy, FNAC is advocated before selecting cases for operative treatment.

\section{REFERENCES:}

1. Kapil U. Health Consequences of Iodine Deficiency. Sultan Qaboos Univ Med J 2007;7(3):267-72.

2. Deiz, JL. Goitre in adult patients aged 55 years and older: Etiology and clinical features in 634 patients. J Gerontal A BioiSci Med Sci 2005;60:920-23.

3. Russell RCG, Norman S, Williams, Christopher JK, Bulstrode. Bailey and Love's Short practice of surgery. The thyroid gland and the thyroglossal tract 2004:782.

4. Gupta KL. Neoplasm of the thyroid gland. Clin Geriatr Med 1995;11:271-90.

5. Mathai V, Idikula J, Fenn AS, Air A. Do long-standing nodular goitres result in malignancies? Aust $N Z J$ Surg 1994;64(3):180-2.

6. Courtney M, Townsend (eds). Sabiston Text book of surgery, thyroid. Hundahl SA, Fleming ID, Fremgen AM et al 1998. A national data base report on 53856 cases of thyroid carcinoma treated in the U.S. 2005

7. Dillmann WH. The Thyroid, Cecil Textbook of Medicine, WB Saunders, 2004.

8. Rios A, Rodriguez JM, Canteras M, Galindo PJ, Balsalobre MD, Parrilla P. Risk factors for malignancy in multinodular goiter 2004;30(1):58-62.

9. Fioretti F, Tavani A, Gallus S, Franceschi S, Negri E, LaVecchia C. Case-control study of thyroid cancer in Northern Italy: attributable risk. Int $\mathrm{J}$ Epidemiol 1999;28(4):626-30.

10. Koh KB, Chang KW. Carcinoma in multinodular goiter. $\mathrm{Br}$ J Surg 1992;79(3):266-7.

11. ai-Saleh MS, al-Kattan KM. Incidence of carcinoma in multinodulargoitre in Saudi Arabia. J $R$ Coli Surg Edinb 1994;39(2):06-8.

12. Abu-Eshy SA, Khan AR, Khan GM, al-Humaidi MA, al-Sbehri MY, Malatani TS. Thyroid malignancy in multinodulargoitre and solitary nodule. $J R$ Coli Surg Edinb 1995;40(5):310-2.

13. Irshad AS, Girivasan M, Ramesh V, Santhosh JA. High incidence of thyroid cancer in toxic multinodular goiters. Asia-Pacific J of Clin Oncol 2007;3(3):119-24. 